\title{
A Straightforward Substitution Strategy to Tune BODIPY Dyes Spanning the Near-Infrared Region via Suzuki-Miyaura Cross-Coupling
}

\author{
Guanglei Li ${ }^{1}$, Yu Otsuka ${ }^{1}$, Takuya Matsumiya ${ }^{1}$, Toshiyuki Suzuki ${ }^{2}$, Jianye $\mathrm{Li}^{2}$, \\ Masashi Takahashi ${ }^{2,3}$ and Koji Yamada ${ }^{1,4, *}$ \\ 1 Division of Materials Science, Graduate School of Environmental Science, Hokkaido University, \\ Sapporo 0860-0810, Japan; li_g1@eis.hokudai.ac.jp (G.L.); y_outsuka214@eis.hokudai.ac.jp (Y.O.); \\ hokkaidou4005@hotmail.co.jp (T.M.) \\ 2 Laboratory of Animal Genetics and Reproduction, Graduate School of Agriculture, Hokkaido University, \\ Sapporo 060-8589, Japan; d-7-shk@eis.hokudai.ac.jp (T.S.); lijianye218@163.com (J.L.); \\ mmasashi@anim.agr.hokudai.ac.jp (M.T.) \\ 3 Global station for Food, Land and Water Resources, Global Institution for Collaborative Research and \\ Education, Hokkaido University, Sapporo 060-0815, Japan \\ 4 Division of Materials Science, Faculty of Environmental Earth Science, Hokkaido University, \\ Sapporo 0860-0810, Japan \\ * Correspondence: yamada@ees.hokudai.ac.jp; Tel.: +81-011-706-2254
}

Received: 2 July 2018; Accepted: 24 July 2018; Published: 27 July 2018

\begin{abstract}
In this study, a series of new red and near-infrared (NIR) dyes derived from 4,4-difluoro-4-bora-3a,4a-diaza-s-indacene (BODIPY) were developed by introducing thiophene and its derivatives to the 3- and 5- positions of the dichloroBODIPY core. For the first time, cyclictriol boronates and $\mathrm{N}$-methyliminodiacetic acid (MIDA) boronate were used as organoboron species to couple with 3,5-dichloroBODIPY via the one-step Suzuki-Miyaura cross-coupling. Six kinds of thieno-expended BODIPY dyes were synthesized in acceptable yields ranging from $31 \%$ to $79 \%$. All six dyes showed different absorption and emission wavelengths spanning a wide range (c.a. 600-850 nm) in the red and NIR regions with relatively high quantum yields (19-85\%). Cellular imaging of 8-(2,6-dimethylphenyl)-re3,5-di(2-thienyl)-BODIPY (dye 1) was conducted using bovine cumulus cells, and the fluorescence microscopy images indicated that the chromophore efficiently accumulated and was exclusively localized in the cytoplasm, suggesting it could be utilized as a subcellular probe. All six dyes were characterized using $1 \mathrm{H}-\mathrm{NMR}$ and mass spectrometry.
\end{abstract}

Keywords: BODIPY; near-infrared; fluorescence; cellular imaging; Suzuki-Miyaura cross-coupling

\section{Introduction}

Long-wavelength dyes, which absorb and emit light in the far-red and near-infrared (NIR) region, have found extensive applications in biology [1] as the spectra in the NIR region has many advantages, such as enhanced sensitivity owing to high contrast and low background noise, deep penetration in tissue, and less damage to organisms. The demand for NIR dyes has greatly stimulated the interest in the design of various novel NIR chromophores that feature optimized properties.

Cyanine is one of the most studied fluorescent dyes. However, its fluorescence tends to be weak and presents low quantum yields except for a few examples [2,3], hence impeding its application in biology. Many NIR dyes have similar drawbacks, while some of them are difficult to synthesize. Therefore, development of alternative NIR dyes and a straightforward modification strategy are imperative. 
4,4-difluoro-4-bora-3a,4a-diaza-s-indacene (BODIPY) derivatives-also known as boron dipyrromethene-have been widely used over the past two decades due to their outstanding characteristics, such as high molar absorption coefficients, intense fluorescence quantum yields, high stability, and tunable spectroscopic and photophysical properties [4,5]. However, the relatively short wavelength of excitation and emission maxima (generally within 500-600 nm) limit the application of BODIPY chromophores.

Various strategies have been employed to promote the absorption and emission wavelengths of BODIPY dyes to the far-red and NIR regions. Some examples include the extension of $\pi$-conjugation length $[6,7]$, rigidification of rotatable moieties [8,9], the introduction of a nitrogen atom in the meso-position to form aza-BODIPY dyes [10,11], and the formation of a "push-pull" motif [12,13].

It has been known that introduction of thiophene subunits to BODIPY results in a remarkable bathochromic shift, and many of them exhibit important optical properties [14-16]. Strikingly, in previous research, we found that solvatochromic dyes containing thiophene emitted longer wavelength than other well-known solvatochromic dyes [17], such as $\mathrm{N}$-(2-aminoethyl)-4-[5-[4-(dimethylamino)phenyl]-2-oxazolyl]benzenesulfonamide (Dapoxyl SEDA) [18], $N, N$-dimethyl-6-propionyl-2-naphthylamine (PRODAN) [19], and 1-anilinonaphthalene-8-sufonate (ANS) [20]. Therefore, we expect to tune the absorption and emission wavelengths of BODIPYs by introducing different moieties of solvatochromic dyes on the BODIPY core.

The development of NIR dyes generally requires a sophisticated design that involves tedious modification steps. Therefore, it is crucial to develop a simple and systematic approach to tune the wavelengths of BODIPY dyes spanning the NIR region, essentially with high quantum yield.

A few examples of thienyl groups-modified 3,5-disubstituted BODIPY dyes using Stille coupling have been reported [21-24]. However, organotin compounds are highly toxic, and it is very hard to purify organotin substrates due to their instability on silica or alumina columns. This hinders extensive application of the organotin compounds.

Suzuki-Miyaura cross-coupling - one of the most efficient methods for the construction of C-C bonds-has been employed to couple BODIPY core with phenyl or thienyl subunits $[25,26]$. To the best of our knowledge, only two examples of modified thiophene units have been reported to couple with 3,5-dihaloBODIPY using Suzuki-Miyaura cross-coupling; however, they were in low yield ( 14\%) [27]. Basically, there are no available information showing successful introduction of electron donating group-modified thiophene to the 3- and 5- positions of BODIPY core via the cross-coupling reaction. This is mostly due to two reasons: (1) the Suzuki-Miyaura cross-coupling of five-membered boronic acid could be problematic [28,29]; and (2) the first cross-coupling reaction would significantly reduce the reactivity of the remaining halogen.

Herein, we report a straightforward method to introduce thienyl and thienyl derivatives onto a specific 3,5-dichloroBODIPY scaffold via a one-step Suzuki-Miyaura cross-coupling to tune the wavelengths toward the red and NIR regions. Using cyclictriol boronates and N-methyliminodiacetic acid (MIDA) boronate as organoboron species, a set of red and NIR BODIPY dyes were synthesized (Figure 1) in acceptable yields ranging from $31 \%$ to $51 \%$ under mild reaction conditions, all of which exhibited relatively high quantum yields in the range of 0.19 to 0.85 . This is the first time that electron donating group-modified thiophene parts were efficiently introduced onto the 3- and 5- positions of the BODIPY core via Suzuki-Miyaura cross-coupling. 


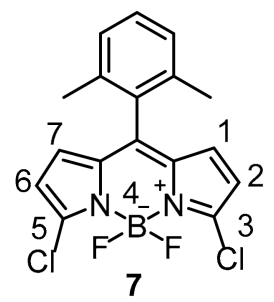

$1 \mathrm{R}=\cdots-{ }_{S}$

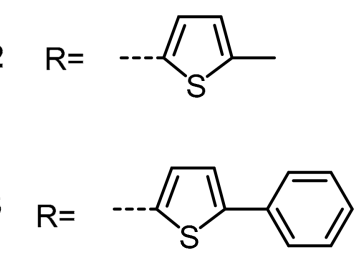

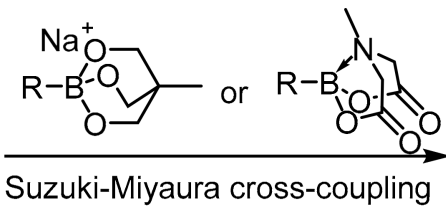

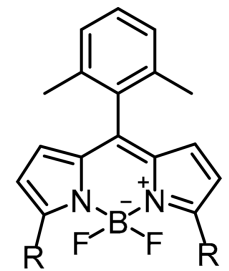

4

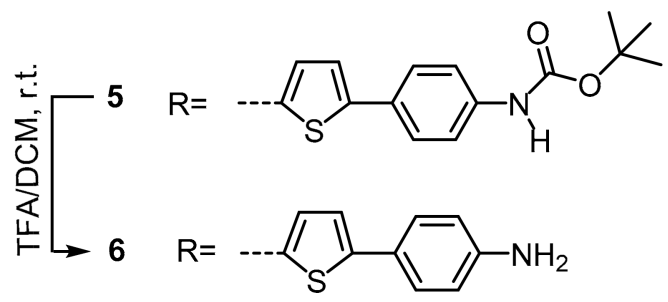

Figure 1. Synthetic scheme to 4,4-difluoro-4-bora-3a,4a-diaza-s-indacene (BODIPY) dyes 1-6. TFA = trifluoroacetic acid.

\section{Materials and Methods}

\subsection{General Experimental}

All commercially available solvents and reagents were purchased from suppliers (Sigma-Aldrich Chemical Company (St. Louis, MO, USA), Wako Pure Chemical Industries (Osaka, Japan) or Tokyo Chemical Industry (Tokyo, Japan)), and were used as received unless otherwise noted. Reactions were monitored with high-performance thin-layer chromatography (HPLC; silica gel 60, 0.25mm, F-254, Merck KGaA, Darmstadt, Germany), which were visualized with UV light or/and by a color reaction staining with phosphomolybdic acid solution (5\% $w / v$ in ethanol). Column chromatography was performed using silica gel 60 mesh 230-400 (Wako Pure Chemical Industries, Osaka, Japan).

${ }^{1} \mathrm{H}-\mathrm{NMR}$ spectra were recorded on a JEOL $400(400 \mathrm{MHz})$ spectrometer (JEOL Ltd., Tokyo, Japan) at room temperature. Chemical shifts were expressed in parts per million (ppm) relative to the standard reference tetramethylsilane (TMS) (0 ppm). Coupling constants $(J)$ were expressed in Hertz. Mass spectra were carried out on a Thermo Scientific Exactive (Thermo Fisher Scientific K.K., Tokyo, Japan) under electrospray ionization (ESI) or atmospheric pressure chemical ionization (APCI) conditions. UV-visible absorption spectra were performed on a JASCO V-560 spectrophptometer (JASCO Corporation, Tokyo, Japan), and fluorescence spectra and fluorescence quantum yields were measured with Hamamatsu Photonics Quantaurus-QY Absolute PL quantum yield spectrometer C11347 (Hamamatsu Photonics K.K., Hamamatsu, Japan); fluorescence microscopy images were carried out on Leica DMi 8 fluorescence microscope (Leica Camera AG, Wetzlar, Germany).

\subsection{Synthesis of BODIPY Dyes 1-6}

\subsubsection{General Procedure: Synthesis of Dyes 1-4}

The starting material-3,5-dichloroBODIPY core (compound 7)—was synthesized according to the previously published method [30]. Compound 7 (1 equiv), Palladium (II) acetate [Pd(OAc) 2$]$ (10 mol \%), 2-Dicyclohexylphosphino-2' ,6'-dimethoxybiphenyl (SPhos) (20 mol \%), CuCl (0.4 equiv) and respective boronates ( 3 equiv) were placed in a two-necked round bottom flask. Prior to the addition of $N, N$-dimethylformamide (DMF), the flask was purged with $\mathrm{N}_{2}$ three times. The reaction was stirred at $60{ }^{\circ} \mathrm{C}$ for $24 \mathrm{~h}$, and the mixture was allowed to cool to room temperature, then extracted with ethyl acetate and washed with $\mathrm{H}_{2} \mathrm{O}$ and brine (saturated $\mathrm{NaCl}$ solution) successively. The organic 
layer was collected and dried over $\mathrm{Na}_{2} \mathrm{SO}_{4}$ and evaporated to dryness under reduced pressure. The crude sample was purified by silica gel column chromatography using eluent gradients with the eluent pair hexane/ethyl acetate.

Synthesis of 8-(2,6-Dimethylphenyl)-3,5-di(2-thienyl)-BODIPY (1)

Prepared according to the general procedure using compound 7 (91 mg, $0.25 \mathrm{mmol}$ ), (2-thiophene) cyclic-triolborate sodium salt (175 mg, $0.75 \mathrm{mmol}), \mathrm{Pd}(\mathrm{OAc})_{2}(6 \mathrm{mg}, 0.025 \mathrm{mmol})$, SPhos $(21 \mathrm{mg}$, $0.05 \mathrm{mmol}), \mathrm{CuCl}(10 \mathrm{mg}, 0.1 \mathrm{mmol})$ and DMF $(2.5 \mathrm{~mL})$ to afford the desired product as a dark green solid $(54 \mathrm{mg}, 47 \%) .{ }^{1} \mathrm{H}-\mathrm{NMR}\left(400 \mathrm{MHz}, \mathrm{CDCl}_{3}\right): \delta=8.24(\mathrm{dd}, J=3.8 \mathrm{~Hz}, J=1 \mathrm{~Hz}, 2 \mathrm{H}), \delta=7.49$ $(\mathrm{dd}, J=5.4 \mathrm{~Hz}, J=1 \mathrm{~Hz}, 2 \mathrm{H}), \delta=7.31 \sim 7.27(\mathrm{~m}, 1 \mathrm{H}), \delta=7.21(\mathrm{dd}, J=4.9 \mathrm{~Hz}, J=3.9 \mathrm{~Hz}, 2 \mathrm{H}), \delta=7.15$ $(\mathrm{d}, J=7.8 \mathrm{~Hz}, 2 \mathrm{H}), \delta=6.76(\mathrm{~d}, J=4.3 \mathrm{~Hz}, 2 \mathrm{H}), \delta=5.54(\mathrm{~d}, J=3.9 \mathrm{~Hz}, 2 \mathrm{H}), \delta=2.20(\mathrm{~s}, 6 \mathrm{H})$. ESI-FTMS $(m / z)$ Calculated for $\mathrm{C}_{25} \mathrm{H}_{19} \mathrm{BF}_{2} \mathrm{~N}_{2} \mathrm{~S}_{2}: 460.11$; found $[\mathrm{M}+\mathrm{H}]^{+}: 461.12$.

Synthesis of 8-(2,6-Dimethylphenyl)-3,5-di(5-methyl-2-thienyl)-BODIPY (2)

Prepared according to the general procedure using compound 7 (182 $\mathrm{mg}, 0.5 \mathrm{mmol})$, 2-(5-methylthiophene) cyclic-triolborate sodium salt ( $372 \mathrm{mg}, 1.5 \mathrm{mmol}), \mathrm{Pd}(\mathrm{OAc})_{2}(11 \mathrm{mg}, 0.05 \mathrm{mmol})$, SPhos (41 mg, $0.1 \mathrm{mmol}), \mathrm{CuCl}(20 \mathrm{mg}, 0.2 \mathrm{mmol})$ and DMF (5 mL) to afford the desired product as a dark green solid $(125 \mathrm{mg}, 51 \%) .{ }^{1} \mathrm{H}-\mathrm{NMR}\left(400 \mathrm{MHz}, \mathrm{CDCl}_{3}\right): \delta=8.01(\mathrm{~d}, J=3.4 \mathrm{~Hz}, 2 \mathrm{H})$, $\delta=7.33-7.24(\mathrm{~m}, 1 \mathrm{H}), \delta=7.13(\mathrm{~d}, J=7.3 \mathrm{~Hz}, 2 \mathrm{H}), \delta=6.86(\mathrm{dd}, \mathrm{J}=3.9 \mathrm{~Hz}, J=1.0 \mathrm{~Hz}, 1 \mathrm{H}), \delta=6.67$ $(\mathrm{d}, J=4.4 \mathrm{~Hz}, 2 \mathrm{H}), \delta=6.48(\mathrm{~d}, J=4.4 \mathrm{~Hz}, 2 \mathrm{H}), \delta=2.56(\mathrm{~s}, 6 \mathrm{H}), \delta=2.19(\mathrm{~s}, 6 \mathrm{H})$. ESI-FTMS $(\mathrm{m} / \mathrm{z})$ Calculated for $\mathrm{C}_{27} \mathrm{H}_{23} \mathrm{BF}_{2} \mathrm{~N}_{2} \mathrm{~S}_{2}$ : 488.14 ; found $[\mathrm{M}+\mathrm{H}]^{+}$: 489.15 .

Synthesis of 8-(2,6-Dimethylphenyl)-3,5-di[(5-phenyl(2-thienyl)]-BODIPY (3)

Prepared according to the general procedure using compound 7 (91 $\mathrm{mg}, 0.25 \mathrm{mmol}$ ), S2 (see supplementary materials) $(240 \mathrm{mg}, 0.75 \mathrm{mmol}), \mathrm{Pd}(\mathrm{OAc})_{2}(6 \mathrm{mg}, 0.025 \mathrm{mmol})$, SPhos $(21 \mathrm{mg}$, $0.05 \mathrm{mmol}), \mathrm{CuCl}(10 \mathrm{mg}, 0.1 \mathrm{mmol})$ and DMF $(2.5 \mathrm{~mL})$ to afford the desired product as a dark green solid $(54 \mathrm{mg}, 35 \%) .{ }^{1} \mathrm{H}-\mathrm{NMR}\left(400 \mathrm{MHz}, \mathrm{CDCl}_{3}\right): \delta=8.27(\mathrm{~d}, J=3.9 \mathrm{~Hz}, 2 \mathrm{H}), \delta=7.69(\mathrm{~d}, J=7.4 \mathrm{~Hz}$, $4 \mathrm{H}), \delta=7.45-7.40(\mathrm{~m}, 6 \mathrm{H}), \delta=7.34(\mathrm{~d}, J=7.3 \mathrm{~Hz}, 2 \mathrm{H}), \delta=7.31 \sim 7.26(\mathrm{~m}, 1 \mathrm{H}), \delta=7.16(\mathrm{~d}, J=7.6 \mathrm{~Hz}, 2 \mathrm{H})$, $\delta=6.80(\mathrm{~d}, J=4.3 \mathrm{~Hz}, 2 \mathrm{H}), \delta=6.54(\mathrm{~d}, J=4.3 \mathrm{~Hz}, 2 \mathrm{H}), \delta=2.22(\mathrm{~s}, 6 \mathrm{H})$. ESI-FTMS $(m / z)$ Calculated for $\mathrm{C}_{37} \mathrm{H}_{27} \mathrm{BF}_{2} \mathrm{~N}_{2} \mathrm{~S}_{2}$ : 612.17; found [M] $]^{+}$: 612.17 .

Synthesis of 8-(2,6-Dimethylphenyl)-3,5-di[(5-phenyl(2-thienyl)]-BODIPY (4)

Prepared according to the general procedure using compound 7 (182 mg, $0.5 \mathrm{mmol})$, S6 (see supplementary materials) (510 mg, $1.5 \mathrm{mmol}), \mathrm{Pd}(\mathrm{OAc})_{2}(11 \mathrm{mg}, 0.05 \mathrm{mmol})$, SPhos (41 mg, $\left.0.1 \mathrm{mmol}\right)$, $\mathrm{CuCl}(20 \mathrm{mg}, 0.2 \mathrm{mmol})$ and DMF (5 mL) to afford the desired product as a purple solid (129 $\mathrm{mg}$, $38 \%) .{ }^{1} \mathrm{H}-\mathrm{NMR}\left(400 \mathrm{MHz}, \mathrm{CDCl}_{3}\right): \delta=8.24(\mathrm{~d}, J=4.1 \mathrm{~Hz}, 2 \mathrm{H}), \delta=7.62(\mathrm{~d}, J=8.8 \mathrm{~Hz}, 4 \mathrm{H}), \delta=7.33$ $(\mathrm{d}, J=4.0 \mathrm{~Hz}, 2 \mathrm{H}), \delta=7.30 \sim 7.26(\mathrm{~m}, 1 \mathrm{H}), \delta=7.15(\mathrm{~d}, J=7.7 \mathrm{~Hz}, 2 \mathrm{H}), \delta=6.95(\mathrm{~m}, 1 \mathrm{H}), \delta=6.78$ $(\mathrm{d}, J=4.4 \mathrm{~Hz}, 2 \mathrm{H}), \delta=6.52(\mathrm{~d}, J=4.4 \mathrm{~Hz}, 2 \mathrm{H}), \delta=3.86(\mathrm{~s}, 6 \mathrm{H}), \delta=2.21(\mathrm{~s}, 6 \mathrm{H})$. ESI-FTMS $(\mathrm{m} / \mathrm{z})$ Calculated for $\mathrm{C}_{39} \mathrm{H}_{31} \mathrm{BF}_{2} \mathrm{~N}_{2} \mathrm{O}_{2} \mathrm{~S}_{2}: 672.19$, found [M] ${ }^{+}: 672.19$.

\subsubsection{Synthesis of 8-(2,6-Dimethylphenyl)-3,5-di[5-(4-BOC-aminophenyl)-2-thienyl)]-BODIPY (5)}

Compound $7 \quad(25 \quad \mathrm{mg}, \quad 0.07 \quad \mathrm{mmol}), \quad \mathrm{Pd}(\mathrm{OAc})_{2} \quad(2 \quad \mathrm{mg}, \quad 0.007 \quad \mathrm{mmol})$, 2-Dicyclohexylphosphino-2' $4^{\prime}, 6^{\prime}$-triisopropylbiphenyl (XPhos) (7 mg, $0.014 \mathrm{mmol}$ ), and MIDA boronate $\mathbf{S 1 0}$ (see supplementary materials) $(88 \mathrm{mg}, 0.21 \mathrm{mmol}$ ) were placed in a two-necked round bottom flask. The flask was then purged with $\mathrm{N}_{2}$ three times before addition of dioxane $(5 \mathrm{~mL})$. The mixture was stirred at ambient temperature for $5 \mathrm{~min}$. Then, $\mathrm{K}_{3} \mathrm{PO}_{4}(0.5 \mathrm{M}, 1 \mathrm{~mL})$ was added, and the reaction mixture was stirred at $60^{\circ} \mathrm{C}$ for two days. The mixture was allowed to cool to room temperature, extracted with ethyl acetate, washed with $\mathrm{H}_{2} \mathrm{O}$ and brine successively. The organic layer was collected, dried over $\mathrm{Na}_{2} \mathrm{SO}_{4}$ and evaporated to dryness under reduced pressure. The crude 
sample was purified by silica gel column chromatography (ethyl acetate: hexane 1: 4) to afford dark green solid $5(18 \mathrm{mg})$ in $31 \%$ yield. ${ }^{1} \mathrm{H}-\mathrm{NMR}\left(400 \mathrm{MHz}, \mathrm{CDCl}_{3}\right): \delta=8.23(\mathrm{~d}, J=4.1 \mathrm{~Hz}, 2 \mathrm{H}), \delta=7.61$ $(\mathrm{d}, J=8.6 \mathrm{~Hz}, 4 \mathrm{H}), \delta=7.42(\mathrm{~d}, J=8.4 \mathrm{~Hz}, 4 \mathrm{H}), \delta=7.36(\mathrm{~d}, J=4.0 \mathrm{~Hz}, 2 \mathrm{H}), \delta=7.30 \sim 7.24(\mathrm{~m}, 1 \mathrm{H})$, $\delta=7.15(\mathrm{~d}, J=7.8 \mathrm{~Hz}, 2 \mathrm{H}), \delta=6.78(\mathrm{~d}, J=4.4 \mathrm{~Hz}, 2 \mathrm{H}), \delta=6.55(\mathrm{bs}, 2 \mathrm{H}), \delta=6.52(\mathrm{~d}, J=4.4 \mathrm{~Hz}, 2 \mathrm{H})$, $\delta=2.21(\mathrm{~s}, 6 \mathrm{H}), \delta=1.54(\mathrm{~s}, 18 \mathrm{H})$. ESI-FTMS $(\mathrm{m} / z)$ Calculated for $\mathrm{C}_{47} \mathrm{H}_{45} \mathrm{BF}_{2} \mathrm{~N}_{4} \mathrm{O}_{4} \mathrm{~S}_{2}: 842.29$, found $[\mathrm{M}-\mathrm{H}]^{+}: 841.29$.

\subsubsection{Synthesis of 8-(2,6-Dimethylphenyl)-3,5-di[5-(4-aminophenyl)-2-thienyl)]-BODIPY (6)}

Dye 5 (26 mg, 0.03 mmol) dissolved in $1 \mathrm{~mL}$ dichloromethane (DCM) was stirred under $\mathrm{N}_{2}$ for $5 \mathrm{~min}$ at $0{ }^{\circ} \mathrm{C}$, followed by dropwise addition of TFA $(60 \mu \mathrm{L})$, and the reaction mixture was stirred for $24 \mathrm{~h}$ at ambient temperature. After cooling to $0^{\circ} \mathrm{C}$, the reaction was quenched with $1 \mathrm{~mL}$ saturated solution of $\mathrm{NaHCO}_{3}$, extracted with ethyl acetate, washed with $\mathrm{H}_{2} \mathrm{O}$ and brine successively. The organic layer was collected, dried over $\mathrm{Na}_{2} \mathrm{SO}_{4}$, and evaporated to dryness under reduced pressure. The crude sample was purified by silica gel column chromatography $\left(\mathrm{CHCl}_{3} 100 \%\right)$ to afford black solid $6(11 \mathrm{mg})$ in 79\% yield. ${ }^{1} \mathrm{H}-\mathrm{NMR}\left(400 \mathrm{MHz}, \mathrm{CDCl}_{3}\right): \delta=8.23(\mathrm{~d}, J=4.2 \mathrm{~Hz}, 2 \mathrm{H}), \delta=7.49$ $(\mathrm{d}, J=8.4 \mathrm{~Hz}, 4 \mathrm{H}), \delta=7.30 \sim 7.24(\mathrm{~m}, 3 \mathrm{H}), \delta=7.14(\mathrm{~d}, J=7.7 \mathrm{~Hz}, 2 \mathrm{H}), \delta=6.76(\mathrm{~d}, J=4.3 \mathrm{~Hz}, 2 \mathrm{H})$, $\delta=6.70(\mathrm{~d}, J=8.4 \mathrm{~Hz}, 4 \mathrm{H}), \delta=6.49(\mathrm{~d}, J=4.3 \mathrm{~Hz}, 2 \mathrm{H}), \delta=2.20(\mathrm{~s}, 6 \mathrm{H})$. ESI-FTMS $(m / z)$ Calculated for $\mathrm{C}_{37} \mathrm{H}_{29} \mathrm{BF}_{2} \mathrm{~N}_{4} \mathrm{~S}_{2}: 642.19$; Found $[\mathrm{M}-\mathrm{H}]^{+}: 641.19$.

\subsection{Collection and Culture of Bovine Cumulus Cells}

Bovine ovaries were obtained from a local slaughterhouse. The ovaries were washed in a sterile solution of saline containing $10 \mathrm{IU} / \mathrm{mL}$ of penicillin and streptomycin. After oocytes pick up, cumulus cells remaining in the follicular fluid were used for the experiment. Collected cumulus cells were transferred to 8 well chamber slide (Watson, Tokyo, Japan) filled with Dulbecco's minimal essential medium (DMEM) containing 5\% fetal bovine serum (FBS). Then, cells were cultured for 1-2 days at $38.0{ }^{\circ} \mathrm{C}$ in a humidified atmosphere of $95 \%$ air and $5 \% \mathrm{CO}_{2}$. After reaching $70-80 \%$ of confluency, each well was washed and replaced with fresh DMEM containing 5\% FBS.

\subsection{Cellular Staining Study of Dye $\mathbf{1}$}

Cell staining was carried out using dye 1. Stock dye solution (10 $\mu \mathrm{M}$ in dimethyl sulfoxide) was diluted with DMEM containing 5\% FBS to make final concentration at $0.2 \mu \mathrm{M}$. Hoechst 33242 (Thermo Fisher Scientific, Waltham, MA, USA) was also added to the same medium to stain the nuclei. After $1 \mathrm{~h}$ incubation at $38.0^{\circ} \mathrm{C}$ in $5 \% \mathrm{CO}_{2}$ incubator, the culture medium was removed and the cells were washed with PBS, and fresh culture medium was added to each well. Images were acquired using a fluorescent microscope with DAPI and TexasRed (TX2) filter cubes.

\section{Results and Discussion}

\subsection{Synthesis of Dyes $\mathbf{1}-\mathbf{6}$}

Introduction of a 2,6-dimethylphenyl moiety at the meso-position of BODIPY core is an efficient way to increase the fluorescence quantum yield by restricting the internal rotation of the phenyl ring caused by the two ortho methyl groups [31].

Suzuki-Miyaura cross-coupling often gives undesirable result for heteroaromatic boronate due to the accelerated hydrolytic B-C bond cleavage in basic aqueous condition during Suzuki-Miyaura cross-coupling [32-34]. Cyclictriol boronate is superior as it can undergo Suzuki-Miyaura cross-coupling even in the absence of a base [35], which would diminish the competitive hydrolytic $\mathrm{B}-\mathrm{C}$ bond cleavage during the reaction. In addition, cyclictriol boronate is an air- and water-stable boron reagent. This easy-handling boronate, which has extremely high nucleophilicity [36] and good solubility in organic solvents, tends to have high reactivity coupling with halogens [37]. Thus, the cyclic boronate was applied for this study. 
It has been demonstrated that electron-rich and bulky ligands could facilitate the Suzuki-Miyaura cross-coupling by increasing the rate of the oxidative addition and reductive elimination process $[38,39]$. Moreover, the addition of copper(I) can promote Suzuki-Miyaura cross-coupling [35,40]. Based on this information, dyes 1-4 were synthesized under the optimized conditions and isolated in relatively high yields ranging from $35 \%$ to $51 \%$, considering the fact that electron-neutral or electron-rich aryl chlorides have low reactivity and are regarded as inactivated chlorides [41]. In this disubstitution reaction, an electron donating group at the first substitution step inhibited the reactivity of the monosubstituted intermediates as the donating groups increased the electron density via a resonance donating effect.

The MIDA boronate, obtained from boronic acid [42,43], was also synthesized as an alternative boron reagent for the modification of the BODIPY core. MIDA boronate ester is stable under various conditions and can slowly release the corresponding boronic acid in mild basic aqueous solution [42]. This ester is more effective than the corresponding boronic acid when coupling with chlorides under mild basic aqueous condition [44]. Using the optimized conditions, dye 5 was produced with a yield of $31 \%$, and dye $\mathbf{6}$ was obtained a $79 \%$ yield via reaction of dye 5 with trifluoroacetic acid at room temperature.

Compared to the reported methods using Stille coupling [21-24], the synthetic method described here is advantageous as the reactions were conducted in mild condition $\left(60^{\circ} \mathrm{C}\right)$ with competitive yields, and no toxic regent is involved in the reactions.

\subsection{Spectroscopic and Photophysical Properties of Dyes 1-6}

The spectroscopic characterization of these BODIPY dyes was performed in DCM as shown in Figure 2 and are summarized in Table 1. The absorption and emission maxima could be greatly affected by the introduction of electron donating substitution at 3,5-position $[4,5,8]$. The absorption and emission bands of dyes 1-6 were in the red to NIR regions. The absorption spectra showed a strong $S_{0}$ to $S_{1}$ transition with absorption maxima varying between $621 \mathrm{~nm}$ and $708 \mathrm{~nm}$, and the shoulder peak located at shorter wavelength was ascribed to the $S_{0}$ to $S_{2}$ transition. The emission bands were the mirror images of the absorption ones with moderate Stokes shift; emission maxima were in the range of $640-780 \mathrm{~nm}$.

Unexpectedly, the methyl at the $\alpha$-position of the thiophene in dye 2 induced appreciable bathochromic shifts of $4.78 \times 10^{2} \mathrm{~cm}^{-1}$ in the absorption and $5.20 \times 10^{2} \mathrm{~cm}^{-1}$ in the emission. A similar phenomenon was also found in a previous report, i.e., one additional methyl group red-shifted the absorption and emission maxima by about $2.01 \times 10^{2} \mathrm{~cm}^{-1}$ and $1.64 \times 10^{2} \mathrm{~cm}^{-1}$, respectively [45]. It violated the general assertion that as a weak electron donating group, the methyl group generally has little effect on wavelengths of fluorescent dyes.

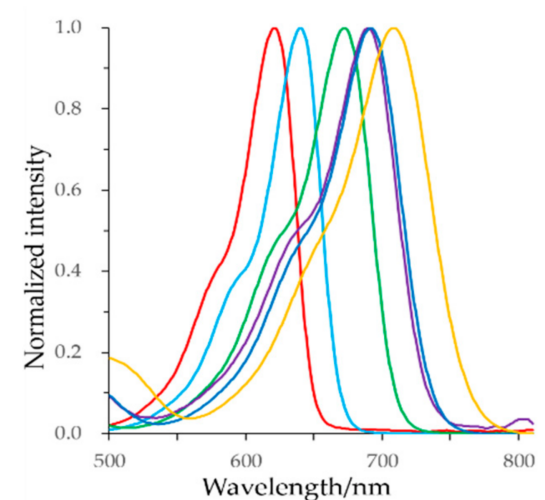

(a)

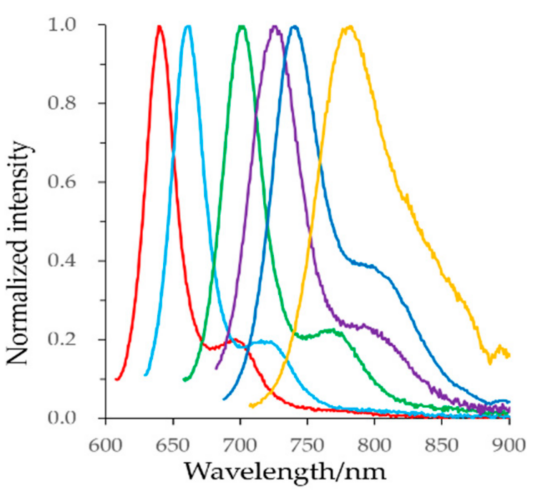

(b)

Figure 2. Normalized absorption (a) and fluorescence (uncorrected) (b) spectra of BODIPYs 1-6 in dichloromethane (DCM) (red, 1; light blue, 2; green, 3; purple, 4; blue, 5; and yellow, 6, respectively). 
Table 1. Spectroscopic data of dyes 1-6 in dichloromethane (DCM).

\begin{tabular}{|c|c|c|c|c|c|}
\hline Dye & $\lambda_{\mathrm{abs}} / \mathrm{nm}$ & $\lambda_{\mathrm{em}} / \mathrm{nm}$ & $\Phi_{\mathrm{f}}$ & $\varepsilon / \mathbf{M}^{-1} \mathrm{~cm}^{-1}$ & Stokes Shift $/ \mathrm{cm}^{-1}$ \\
\hline 1 & 621 & 640 & 0.85 & 69,000 & $4.78 \times 10^{2}$ \\
\hline 2 & 640 & 662 & 0.81 & 66,000 & $5.19 \times 10^{2}$ \\
\hline 3 & 672 & 701 & 0.71 & 75,000 & $6.16 \times 10^{2}$ \\
\hline 4 & 689 & 725 & 0.68 & 78,000 & $7.21 \times 10^{2}$ \\
\hline 5 & 691 & 740 & 0.53 & 82,000 & $9.58 \times 10^{2}$ \\
\hline 6 & 708 & 780 & 0.19 & 72,000 & $13.0 \times 10^{2}$ \\
\hline
\end{tabular}

The extension of $\pi$-conjugation also led to a remarkable bathochromic shift $\left(12.23 \times 10^{2} \mathrm{~cm}^{-1}\right.$ and $13.60 \times 10^{2} \mathrm{~cm}^{-1}$ for the absorbance and emission band, respectively), dye 3 showed an absorption maximum at $672 \mathrm{~nm}$ and the emission at $701 \mathrm{~nm}$. As expected, further extension of the $\pi$-conjugation and the addition of electron donating group increased the bathochromic shift. As a result, the absorption and the emission maxima of dye 6 were shifted to $708 \mathrm{~nm}$ and $780 \mathrm{~nm}$, respectively.

Interestingly, dyes 4 and $\mathbf{5}$ showed similar absorption maximum (c.a. $690 \mathrm{~nm}$ ), but their emission maxima were at $725 \mathrm{~nm}$ and $740 \mathrm{~nm}$, respectively. The difference between the emission maxima may arise from the geometry relaxation of the dyes upon photoexcitation [46]. We anticipate that compared to the methoxy group, the bulky tert-butyloxycarbonyl protecting amine group could induce larger geometry relaxation at the excited state $\left(S_{1}\right.$ state), and the decreased energy gap will produce a larger Stokes shift. The increased wavelengths were likely caused by the combined effects of the extension of the $\pi$-electrons delocalization, the strength of the $\pi$-electron donors, and the sulfur atoms. Therefore, the wavelengths of the synthesized dyes could be fine-tuned using a stronger donating group and/or achieving a longer extension of the $\pi$-conjugation, giving rise to the wavelengths that shifted to lower energy.

Fluorescence quantum yield is one of the most important parameters to evaluate fluorophores. It directly reflects the efficiency of the conversion of absorbed photons into emitted ones. In addition, many far-red and NIR chromophores encounter low fluorescence quantum yield $[3,16]$. To our delight, the bathochromic shift was achieved without compromising the fluorescence quantum yield: dyes 1-5 were quite high in the range of 0.53 to 0.85 . Although for dye 6 , which was synthesized by removing the BOC group from dye 5, a decrease in the fluorescence quantum yield was observed (0.19 in DCM), it still remained at a moderate level. This decrease may result from the formation of hydrogen bonds between the amine groups and hence invoke rapid quenching of the singlet state through intramolecular charge transfer (ICT) $[47,48]$. On the whole, no obvious fluorescence quenching was observed, indicating that the modification method is a feasible way to develop NIR BODIPY dyes.

\subsection{Cellular Imaging of Dye $\mathbf{1}$}

To assert the performance of our BODIPY dyes in practical use, cellular imaging was conducted. Dye 1 was selected as the representative dye to study cellular uptake for its inherent high fluorescent quantum yield, which would enable facile visualization with fluorescence microscopy in the red region. To simplify the cellular observation, a dual staining experiment was performed. $2 \mu \mathrm{M}$ aqueous dye 1 and Hoechst were incubated with bovine cumulus cells for $1 \mathrm{~h}$ at $38^{\circ} \mathrm{C}$. Excitation and observation of dye 1 and Hoechst were achieved using TX2 and DAPI filter cubes, respectively. Dye 1 and Hoechst showed efficient accumulation in the cells, as shown in Figure 3b,c. Dye $\mathbf{1}$ appeared to be accumulated in the cytoplasm (red color) of the cell, but not in the nucleus (black area), as shown in Figure $3 b$. We further merged these two images, and an image of clear contrast (Figure 3d) was obtained. As we know that Hoechst specifically stains the nuclei other than the cytoplasm, the images indicated that dye $\mathbf{1}$ was exclusively localized in the cytoplasm; this suggests dye $\mathbf{1}$ has prospect to be used as a subcellular probe. 


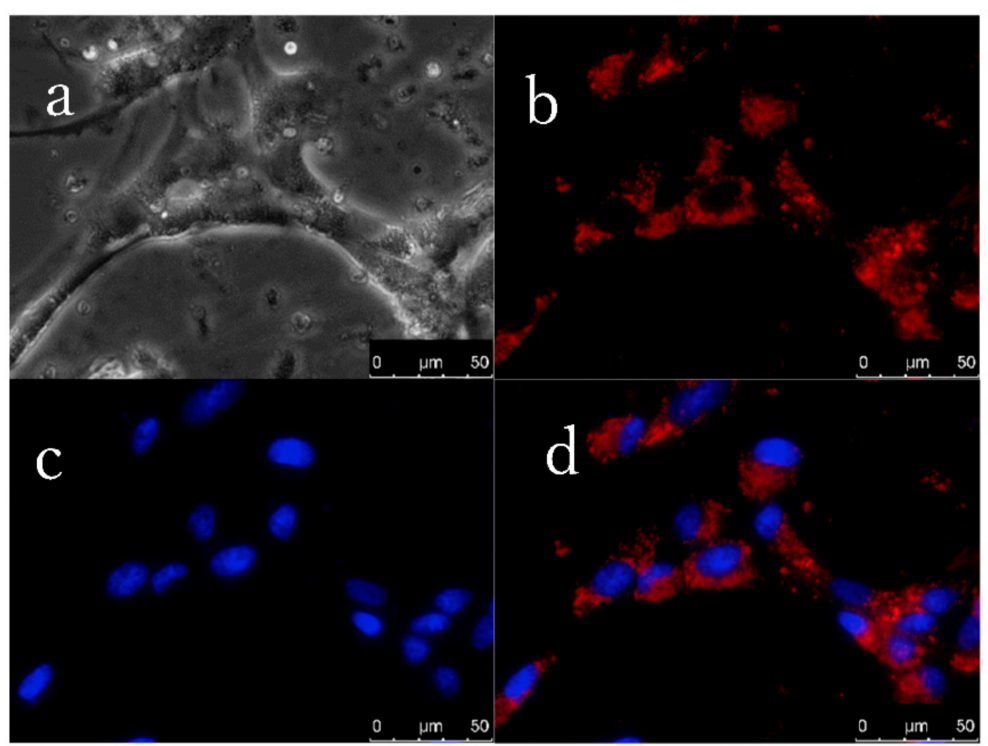

Figure 3. Fluorescence colocalization images of dye $\mathbf{1}$ and Hoechst 33242 in live bovine cumulus cells. (a) bright field; (b) cellular uptake of dye 1 in the cytoplasm, TX2 filters (BP 560/40, BP 645/75); (c) Hoechst stained nuclei region, DAPI filters (BP 350/50, BP 460/50); (d) overlay of b/c.

\section{Conclusions}

In this paper, a facile approach to develop red and NIR BODIPY dyes was proposed. Six different red and NIR BODIPY dyes were rationally designed and synthesized from readily available 3,5-dichloroBODIPY via a one-step Suzuki-Miyaura cross-coupling. Dyes 1-6 showed different absorption (621-708 $\mathrm{nm}$ ) and emission (640-780 nm) with relatively high quantum yields (19-85\%) in DCM. Extension of $\pi$-conjugation and the addition of electron donating group increased the bathochromic shift. Dye 6 bearing amine groups exhibited the longest absorption maximum $\lambda_{\text {abs }}$ $(708 \mathrm{~nm})$ and emission maximum $\lambda_{\mathrm{em}}(780 \mathrm{~nm})$ and the longest Stokes shift $(72 \mathrm{~nm})$. The fluorescence microscope images showed efficient uptake of dye $\mathbf{1}$ with bovine cumulus cells, and the dye was exclusively localized in cytoplasm rather than the nucleus.

Supplementary Materials: The following are available online at http:/ /www.mdpi.com/1996-1944/11/8/1297/ s1, Figure S1: Synthesis scheme of dyes 1-4, Figure S2: Synthesis scheme of dyes 5 and 6, Figure S3: Synthesis scheme of S2, Figure S4: Synthesis scheme of S6, Figure S5: Synthesis scheme of S10.

Author Contributions: G.L. and K.Y. conceived and designed the experiments; G.L., O.Y., T.M., T.S., J.L., and M.T. performed the experiments; G.L., T.S., J.L., and M.T. analyzed the data; G.L. wrote the paper.

Funding: This research received no external funding.

Acknowledgments: We are grateful to Takashi Hirano (the University of Electro-Communications) and Hamamatsu Photonics for measuring the emission spectra and quantum yields. We thank the Instrumental Analysis Division of the Hokkaido University for measuring the mass spectra.

Conflicts of Interest: The authors declare no conflict of interest.

\section{References}

1. Escobedo, J.O.; Rusin, O.; Lim, S.; Strongin, R.M. Nir dyes for bioimaging applications. Curr. Opin. Chem. Biol. 2010, 14, 64-70. [CrossRef] [PubMed]

2. Peng, X.; Song, F.; Lu, E.; Wang, Y.; Zhou, W.; Fan, J.; Gao, Y. Heptamethine cyanine dyes with a large stokes shift and strong fluorescence: A paradigm for excited-state intramolecular charge transfer. J. Am. Chem. Soc. 2005, 127, 4170-4171. [CrossRef] [PubMed] 
3. Pansare, V.J.; Hejazi, S.; Faenza, W.J.; Prud'homme, R.K. Review of long-wavelength optical and NIR imaging materials: Contrast agents, fluorophores, and multifunctional nano carriers. Chem. Mater. 2012, 24, $812-827$. [CrossRef] [PubMed]

4. Boens, N.; Leen, V.; Dehaen, W. Fluorescent indicators based on BODIPY. Chem. Soc. Rev. 2012, 41, 1130-1172. [CrossRef] [PubMed]

5. Ulrich, G.; Ziessel, R.; Harriman, A. The chemistry of fluorescent bodipy dyes: Versatility unsurpassed. Angew. Chem. 2008, 47, 1184-1201. [CrossRef] [PubMed]

6. Descalzo, A.B.; Xu, H.-J.; Xue, Z.-L.; Hoffmann, K.; Shen, Z.; Weller, M.G.; You, X.-Z.; Rurack, K. Phenanthrene-fused boron- dipyrromethenes as bright long-wavelength fluorophores. Org. Lett. 2008, 10, 1581-1584. [CrossRef] [PubMed]

7. Jiao, L.; Yu, C.; Liu, M.; Wu, Y.; Cong, K.; Meng, T.; Wang, Y.; Hao, E. Synthesis and functionalization of asymmetrical benzo-fused bodipy dyes. J. Org. Chem. 2010, 75, 6035-6038. [CrossRef] [PubMed]

8. Loudet, A.; Burgess, K. Bodipy dyes and their derivatives: Syntheses and spectroscopic properties. Chem. Rev. 2007, 107, 4891-4932. [CrossRef] [PubMed]

9. Hayashi, Y.; Obata, N.; Tamaru, M.; Yamaguchi, S.; Matsuo, Y.; Saeki, A.; Seki, S.; Kureishi, Y.; Saito, S.; Yamaguchi, S.; et al. Facile synthesis of biphenyl-fused bodipy and its property. Org. Lett. 2012, 14, 866-869. [CrossRef] [PubMed]

10. Zhao, W.; Carreira, E.M. Conformationally restricted aza-bodipy: Highly fluorescent, stable near-infrared absorbing dyes. Chemistry 2006, 12, 7254-7263. [CrossRef] [PubMed]

11. McDonnell, S.O.; O'Shea, D.F. Near-infrared sensing properties of dimethlyamino-substituted $\mathrm{BF}_{2}$-azadipyrromethenes. Org. Lett. 2006, 8, 3493-3496. [CrossRef] [PubMed]

12. Xuan, S.; Zhao, N.; Ke, X.; Zhou, Z.; Fronczek, F.R.; Kadish, K.M.; Smith, K.M.; Vicente, M.G. Synthesis and spectroscopic investigation of a series of push-pull boron dipyrromethenes (bodipys). J. Org. Chem. 2017, 82, 2545-2557. [CrossRef] [PubMed]

13. Yu, Y.H.; Descalzo, A.B.; Shen, Z.; Röhr, H.; Liu, Q.; Wang, Y.W.; Spieles, M.; Li, Y.Z.; Rurack, K.; You, X.Z. Mono-and di (dimethylamino) styryl-substituted borondipyrromethene and borondiindomethene dyes with intense near-infrared fluorescence. Chem.-Asian J. 2006, 1, 176-187. [CrossRef] [PubMed]

14. Zhang, X.; Yu, H.; Xiao, Y. Replacing phenyl ring with thiophene: An approach to longer wavelength aza-dipyrromethene boron difluoride (aza-bodipy) dyes. J. Org. Chem. 2012, 77, 669-673. [CrossRef] [PubMed]

15. Poirel, A.; De Nicola, A.; Ziessel, R. Oligothienyl-bodipys: Red and near-infrared emitters. Org. Lett. 2012, 14, 5696-5699. [CrossRef] [PubMed]

16. Ni, Y.; Wu, J. Far-red and near infrared bodipy dyes: Synthesis and applications for fluorescent pH probes and bio-imaging. Org. Biomol. Chem. 2014, 12, 3774-3791. [CrossRef] [PubMed]

17. Son, S.H.; Abe, Y.; Yuasa, M.; Yamagishi, Y.; Sakai, N.; Ayabe, T.; Yamada, K. A systematic analysis of aromatic heterocyclic rings in solvatochromic fluorophores. Chem. Lett. 2011, 40, 378-380. [CrossRef]

18. Diwu, Z.; Lu, Y.; Zhang, C.; Klaubert, D.H.; Haugland, R.P. Fluorescent molecular probes ii. The synthesis, spectral properties and use of fluorescent solvatochromic dapoxyl dyes. Photochem. Photobiol. 1997, 66, 424-431. [CrossRef]

19. Weber, G.; Farris, F.J. Synthesis and spectral properties of a hydrophobic fluorescent probe: 6-propionyl-2-(dimethylamino) naphthalene. Biochemistry 1979, 18, 3075-3078. [CrossRef] [PubMed]

20. Slavik, J. Anilinonaphthalene sulfonate as a probe of membrane-composition and function. Biochim. Biophys. Acta 1982, 694, 1-25. [CrossRef]

21. Forgie, J.C.; Skabara, P.J.; Stibor, I.; Vilela, F.; Vobecka, Z. New redox stable low band gap conjugated polymer based on an EDOT-BODIPY-EDOT repeat unit. Chem. Mater. 2009, 21, 1784-1786. [CrossRef]

22. Liao, J.; Wang, Y.; Xu, Y.; Zhao, H.; Xiao, X.; Yang, X. Synthesis, optical and electrochemical properties of novel meso-triphenylamine-bodipy dyes with aromatic moieties at 3,5-positions. Tetrahedron 2015, 71, 5078-5084. [CrossRef]

23. Mirloup, A.; Leclerc, N.; Rihn, S.; Bura, T.; Bechara, R.; Hébraud, A.; Lévêque, P.; Heiser, T.; Ziessel, R. A deep-purple-grey thiophene-benzothiadiazole-thiophene bodipy dye for solution-processed solar cells. New J. Chem. 2014, 38, 3644-3653. [CrossRef] 
24. Sengupta, S.; Pandey, U.K.; Athresh, E.U. Regioisomeric donor-acceptor-donor triads based on benzodithiophene and bodipy with distinct optical properties and mobilities. RSC Adv. 2016, 6, 73645-73649. [CrossRef]

25. Rihn, S.; Retailleau, P.; Bugsaliewicz, N.; De Nicola, A.; Ziessel, R. Versatile synthetic methods for the engineering of thiophene-substituted bodipy dyes. Tetrahedron Lett. 2009, 50, 7008-7013. [CrossRef]

26. Rohand, T.; Qin, W.; Boens, N.; Dehaen, W. Palladium-catalyzed coupling reactions for the functionalization of bodipy dyes with fluorescence spanning the visible spectrum. Eur. J. Org. Chem. 2006, 2006, 4658-4663. [CrossRef]

27. Lakhe, D.; Jairaj, K.K.; Pradhan, M.; Ladiwala, U.; Agarwal, N. Synthesis and photophysical studies of heteroaryl substituted-bodipy derivatives for biological applications. Tetrahedron Lett. 2014, 55, 7124-7129. [CrossRef]

28. Kinzel, T.; Zhang, Y.; Buchwald, S.L. A new palladium precatalyst allows for the fast suzuki-miyaura coupling reactions of unstable polyfluorophenyl and 2-heteroaryl boronic acids. J. Am. Chem. Soc. 2010, 132, 14073-14075. [CrossRef] [PubMed]

29. Barder, T.E.; Walker, S.D.; Martinelli, J.R.; Buchwald, S.L. Catalysts for suzuki-miyaura coupling processes: Scope and studies of the effect of ligand structure. J. Am. Chem. Soc. 2005, 127, 4685-4696. [CrossRef] [PubMed]

30. Hafuka, A.; Kando, R.; Ohya, K.; Yamada, K.; Okabe, S.; Satoh, H. Substituent effects at the 5-position of 3-[bis (pyridine-2-ylmethyl) amino]-bodipy cation sensor used for ratiometric quantification of $\mathrm{cu}^{2+}$. Bull. Chem. Soc. Jpn. 2014, 88, 447-454. [CrossRef]

31. Yamada, K.; Toyota, T.; Takakura, K.; Ishimaru, M.; Sugawara, T. Preparation of bodipy probes for multicolor fluorescence imaging studies of membrane dynamics. New J. Chem. 2001, 25, 667-669. [CrossRef]

32. Brown, R.D.; Buchanan, A.S.; Humffray, A.A. Protodeboronation of thiophenboronic acids. Aust. J. Chem. 1965, 18, 1521-1525. [CrossRef]

33. Campeau, L.-C.; Fagnou, K. Applications of and alternatives to $\pi$-electron-deficient azine organometallics in metal catalyzed cross-coupling reactions. Chem. Soc. Rev. 2007, 36, 1058-1068. [CrossRef] [PubMed]

34. Tyrrell, E.; Brookes, P. The synthesis and applications of heterocyclic boronic acids. Synth.-Stuttg. 2003, 2003, 469-483. [CrossRef]

35. Yamamoto, Y.; Takizawa, M.; Yu, X.Q.; Miyaura, N. Cyclic triolborates: Air-and water-stable ate complexes of organoboronic acids. Angew. Chem. Int. Ed. 2008, 47, 928-931. [CrossRef] [PubMed]

36. Lennox, A.J.; Lloyd-Jones, G.C. Selection of boron reagents for suzuki-miyaura coupling. Chem. Soc. Rev. 2014, 43, 412-443. [CrossRef] [PubMed]

37. Li, G.Q.; Yamamoto, Y.; Miyaura, N. Double-coupling of dibromo arenes with aryltriolborates for synthesis of diaryl-substituted planar frameworks. Tetrahedron 2011, 67, 6804-6811. [CrossRef]

38. Galardon, E.; Ramdeehul, S.; Brown, J.M.; Cowley, A.; Hii, K.K.; Jutand, A. Profound steric control of reactivity in aryl halide addition to bisphosphane palladium(0) complexes. Angew. Chem. 2002, 41, 1760-1763. [CrossRef]

39. Martin, R.; Buchwald, S.L. Palladium-catalyzed suzuki-miyaura cross-coupling reactions employing dialkylbiaryl phosphine ligands. Acc. Chem. Res. 2008, 41, 1461-1473. [CrossRef] [PubMed]

40. Deng, J.Z.; Paone, D.V.; Ginnetti, A.T.; Kurihara, H.; Dreher, S.D.; Weissman, S.A.; Stauffer, S.R.; Burgey, C.S. Copper-facilitated suzuki reactions: Application to 2-heterocyclic boronates. Org. Lett. 2009, 11, 345-347. [CrossRef] [PubMed]

41. Littke, A.F.; Fu, G.C. Palladium-catalyzed coupling reactions of aryl chlorides. Angew. Chem. 2002, 41, 4176-4211. [CrossRef]

42. Gillis, E.P.; Burke, M.D. A simple and modular strategy for small molecule synthesis: Iterative suzuki-miyaura coupling of b-protected haloboronic acid building blocks. J. Am. Chem. Soc. 2007, 129, 6716-6717. [CrossRef] [PubMed]

43. Grob, J.E.; Nunez, J.; Dechantsreiter, M.A.; Hamann, L.G. One-pot reductive amination and suzuki-miyaura cross-coupling of formyl aryl and heteroaryl mida boronates in array format. J. Org. Chem. 2011, 76, 4930-4940. [CrossRef] [PubMed]

44. Knapp, D.M.; Gillis, E.P.; Burke, M.D. A general solution for unstable boronic acids: Slow-release cross-coupling from air-stable mida boronates. J. Am. Chem. Soc. 2009, 131, 6961-6963. [CrossRef] [PubMed] 
45. Sobenina, L.N.; Petrova, O.V.; Petrushenko, K.B.; Ushakov, I.A.; Mikhaleva, A.I.; Meallet-Renault, R.; Trofimov, B.A. Synthesis and optical properties of difluorobora-s-diazaindacene dyes with trifluoromethyl meso-substituents. Eur. J. Org. Chem. 2013, 2013, 4107-4118. [CrossRef]

46. Chen, Y.; Zhao, J.; Guo, H.; Xie, L. Geometry relaxation-induced large stokes shift in red-emitting borondipyrromethenes (bodipy) and applications in fluorescent thiol probes. J. Org. Chem. 2012, 77, 2192-2206. [CrossRef] [PubMed]

47. Musser, A.J.; Neelakandan, P.P.; Richter, J.M.; Mori, H.; Friend, R.H.; Nitschke, J.R. Excitation energy delocalization and transfer to guests within mii 416 cage frameworks. J. Am. Chem. Soc. 2017, 139, 12050-12059. [CrossRef] [PubMed]

48. Neelakandan, P.P.; Jiménez, A.; Nitschke, J.R. Fluorophore incorporation allows nanomolar guest sensing and white-light emission in $\mathrm{m} 416$ cage complexes. Chem. Sci. 2014, 5, 908-915. [CrossRef]

C 2018 by the authors. Licensee MDPI, Basel, Switzerland. This article is an open access article distributed under the terms and conditions of the Creative Commons Attribution (CC BY) license (http:/ / creativecommons.org/licenses/by/4.0/). 